\title{
WestVirginiaUniversity
}

THE RESEARCH REPOSITORY @ WVU

Graduate Theses, Dissertations, and Problem Reports

2007

\section{Food and environment as predictors of obesity in rural West Virginia}

Leah W. Gecheo

West Virginia University

Follow this and additional works at: https://researchrepository.wvu.edu/etd

\section{Recommended Citation}

Gecheo, Leah W., "Food and environment as predictors of obesity in rural West Virginia" (2007). Graduate Theses, Dissertations, and Problem Reports. 4302.

https://researchrepository.wvu.edu/etd/4302

This Thesis is protected by copyright and/or related rights. It has been brought to you by the The Research Repository @ WVU with permission from the rights-holder(s). You are free to use this Thesis in any way that is permitted by the copyright and related rights legislation that applies to your use. For other uses you must obtain permission from the rights-holder(s) directly, unless additional rights are indicated by a Creative Commons license in the record and/ or on the work itself. This Thesis has been accepted for inclusion in WVU Graduate Theses, Dissertations, and Problem Reports collection by an authorized administrator of The Research Repository @ WVU. For more information, please contact researchrepository@mail.wvu.edu. 
Food and Environment as Predictors of Obesity in Rural West Virginia

\author{
Leah W. Gecheo
}

\author{
Thesis submitted to the \\ Davis College of Agriculture, Forestry and Consumer Sciences \\ at West Virginia University \\ in partial fulfillment of requirements \\ for the Degree of
}

\author{
Master of Science \\ in \\ Human Nutrition and Food
}

Cindy Fitch, Ph.D., RD. Chair

Kristen Matak, Ph.D.

Betty Forbes, M.A., RD., LD

Department of Animal and Nutritional Sciences

Morgantown, West Virginia

2007

Keywords: BMI, Obesity, Food and Environment, Predictors, Rural, West Virginia Copyright 2007 Leah W. Gecheo 


\section{ABSTRACT \\ Food and Environment as Predictors of Obesity in Rural West Virginia Leah Gecheo}

Objective: The objective of this study was to determine the best predictors of childhood obesity in rural West Virginia. This investigation was inspired by the fact that the rate of obesity occurrence in West Virginia is relatively higher than that in the entire nation.

Method: Subjects used were Head Start children participating in food and nutrition program (FNP) in Mercer and McDowell counties in rural West Virginia. The average age was 52 months both Caucasians and African Americans. Study was conducted using USDA validated questionnaires that focused on the diet, feeding attitudes, beliefs and practices. Children's weights and heights were measured on site. Parents' information was by self reporting.

Results: Results indicated that the girls had a higher body mass index (BMI) than boys $(p<0.01)$ and there was no difference between ethnicities. Mother's BMI was correlated to both boys $(p=0.0205)$ and girls $(p=0.034)$.Father's BMI was only associated with girls weight $(p=$ 0.021). Father's influence was more profound in the lifestyle, the kind of food consumed and the overall weight of the children. Father's education was significantly correlated to the weight of the children $(\mathrm{p}=0.024)$, but no significant correlation was observed in mothers' education.

Other significant correlations observed were, presence of TV in the room and weight perception, presence of TV in the room and high fat food consumed, food quality and food control exerted by parents. Fathers' education, presence of TV in the room and nutrition knowledge were good predictors of obesity in this population. Parental perception was found to be the strongest and the only significant predictor (beta $=-0.489, \mathrm{p}<0.0001$ ).

Conclusion: From this study it can be concluded that, for intervention to be successful, parents need to have the right perception of their children weights and understand the health dangers that overweight and obesity poses to the children. 


\section{TABLE OF CONTENTS}

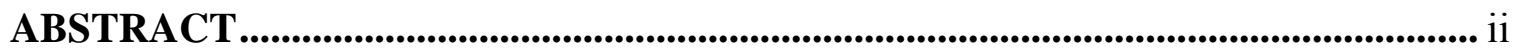

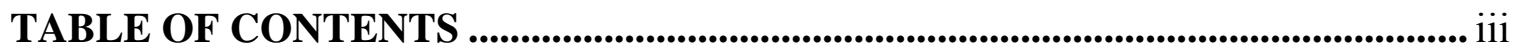

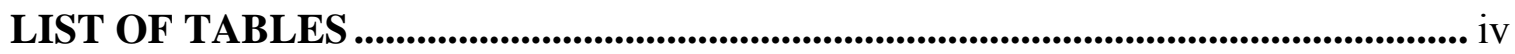

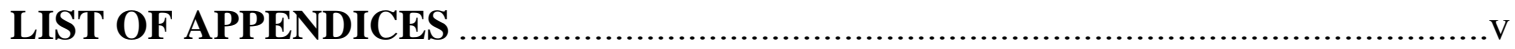

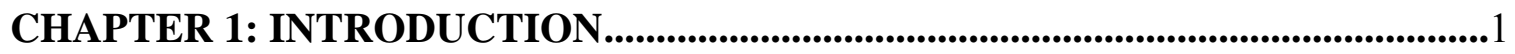

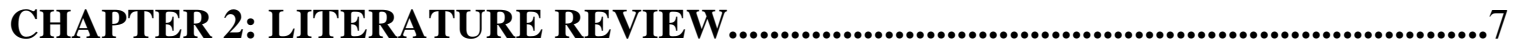

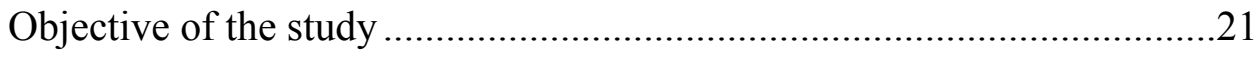

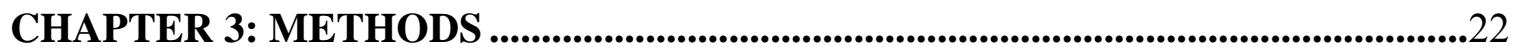

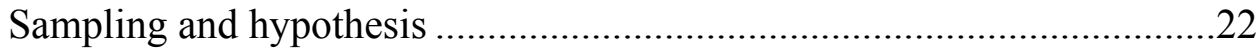

Parental nutrition knowledge .........................................................25

Level of education as compared to nutrition knowledge .......................25

Weight perception compared to BMI z-score....................................26

Parents perception and control..................................................26

Parents control and BMI z-score....................................................2

Food quality and BMI z-score .................................................2

High fat and sugar compared with BMI z-score ..................................27

Presence of TV in child's room ....................................................28

CHAPTER 4: RESULTS .....................................................................................................229

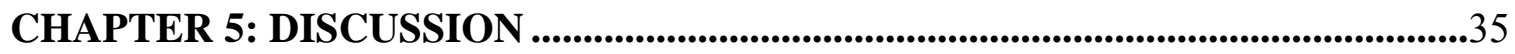

CHAPTER 6: CONCLUSION ...............................................................................42

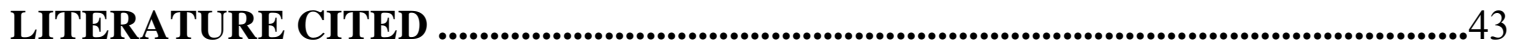

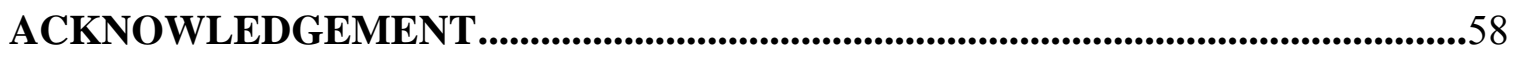




\section{LIST OF TABLES}

Table 1: Description of sample population ….............................................................29

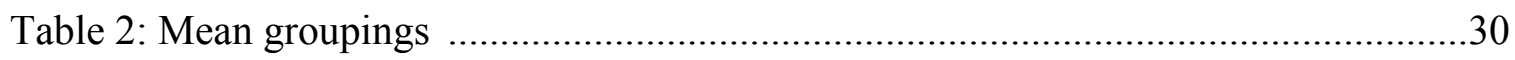

Table 3: Fisher's test for differences in percentile distribution ....................................31

Table 4: Test for differences in percentile distribution between gender ..........................31

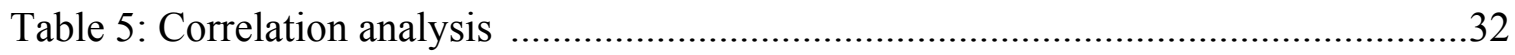

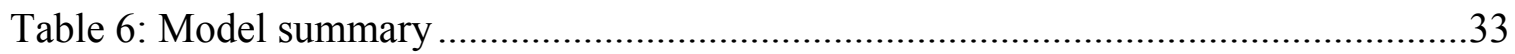

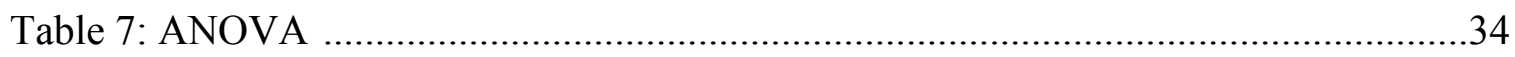

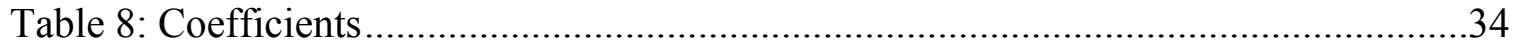




\section{LIST OF APPENDICES}

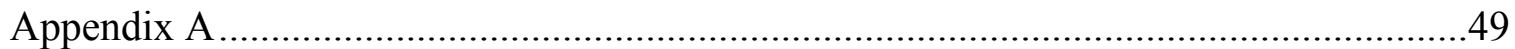

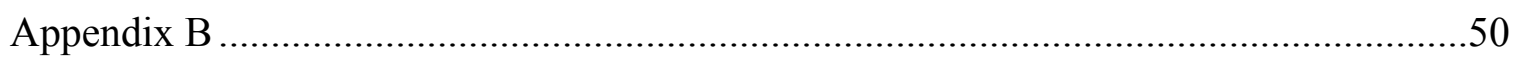

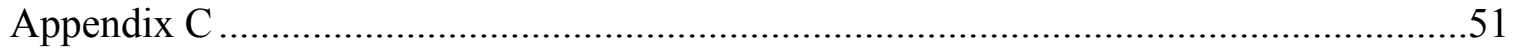

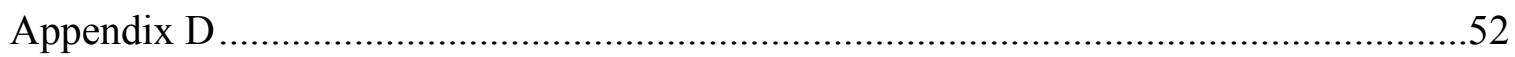

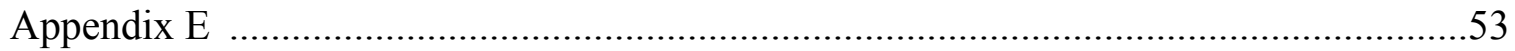




\section{CHAPTER 1 \\ INTRODUCTION}

The prevalence of adult obesity has increased in the United States in the past decade at a rate of $5.9 \%$ and at a rate of $5.2 \%$ in West Virginia. The state's average weight increase has been consistently higher than that in the entire country, $23.2 \%$ compared to $20.1 \%$ in the whole country. This increase is steady in both males and females with average weight increasing from $177.2 \mathrm{lb}$ in men and $142.0 \mathrm{lb}$ in women in 1984 to $194.0 \mathrm{lb}$ and $154.9 \mathrm{lb}$ respectively in 2000 (WV DHHR, 2002). In the two southern counties assessed, Mercer and McDowell counties, sedentary lifestyle is remarkably very high, $65.9 \%$ and $77.2 \%$ respectively, which is a contributing factor to obesity (WV DHHR, Health Statistics Center, 1988- 1993). Between 19951999, the prevalence of adult obesity in these two counties was $17 \%$ and $29 \%$ respectively (WV DHHR, 2002). Between 2000- 2001, CDC estimated costs incurred due to obesity using estimates by Medicaid and Public Employee Insurance Agency (PEIA), 80\% of persons with diabetes were obese costing the state over 2.5 million dollars in obesity related costs. Of those that suffered from cardiovascular diseases, $62 \%$ were obese and obesity related cost in this group was over 20.5 million dollars. Total medical and pharmacy cost due to obesity related illnesses was over 68.2 million dollars (WV DHHR, 2002).

Obesity is not only a major problem with the adults but also with children, predisposing them to life-threatening obesity related diseases later in their lives. Health risks related to obesity include hypertension, diabetes, cardiovascular diseases, sleep apnea, hyperlipidemia, osteoarthritis, abdominal hernias, some cancers, varicose veins, gout, respiratory distress, gallbladder disease, liver malfunctions, complications in pregnancy and surgery and flat feet 
among others(Cataldo et al, 2003). It is second only to tobacco use as the most significant cause of preventable death (Albu et al., 1997).

Obesity has several interrelated causes. A person's genetic make up influences the rate at which energy is utilized by the body. Past research has shown that if both parents are obese there is up to $80 \%$ probability that the child will be obese and if both parents are not obese there is less than $10 \%$ probability that the child will be obese (Perusse et al. 1999). Adoption studies have indicated a genetic inclination of BMI of adopted children to their birth parents and not to their adoptive parents (Stunkard et al, 1986). Lipoprotein lipase (LPL), an enzyme that promotes fat storage in the fat cells and muscle cells has been implicated in obesity. Obese people have been found to have more LPL in their fat cells than do lean people. Obesity gene (ob) in humans codes for a protein leptin. Leptin is a hormone produced and secreted by fat cells in proportion to the amount of fat stored. Increase in body fat stimulates the production of leptin which then stimulates the hypothalamus to suppress appetite, increase energy expenditure and produce fat loss. Fat loss induces an opposite effect by suppressing leptin therefore increasing appetite and decreasing energy expenditure (Cataldo, 2003). People with defective leptin or obesity gene have a higher likelihood of becoming obese. Some obese people have high levels of leptin but have developed resistance to it. This is thought to occur due to over-expression of the hormone as a result of adiposity leading to reduced leptin receptors and decreased signaling. These people are very susceptible to diet- induced obesity.

Fat cell number and size is another cause of obesity. Increase in fat cells and sizes in early childhood and early puberty are major causes of obesity in adulthood. Fat cells increase more rapidly in obese children than in the lean ones (Cataldo, 2003). Fat cells can then expand in size and upon reaching maximum size they may divide. Therefore obesity develops when a 
person's fat cells increase in number, in size and more often both. With weight loss the fat cells shrink in size but not their number, this makes obese people to regain lost weight rapidly. This makes it very important to control excessive weight gain during childhood years when the fat cell numbers are increasing.

Environment is a very important contributor of obesity. This is well established in the study on Pima Indians who have the same genetic makeup but live in different environments, one group living in Arizona and another group living in Mexico (Ravussin et al, 1994). The Mexican Pimas have a mean BMI 7- 10 units less than their Arizona counterparts. Arizona Pimas have the highest prevalence of obesity and non insulin dependent diabetes mellitus. These people have different diet and lifestyle with Arizona Pimas consuming 36\% fat in their diet and Mexican Pimas consuming 23\% fat in their diet. The level of physical activity is remarkably different with those living in Mexico engaging in more rigorous activities than those in Arizona.

Consumption of high fat food has been implicated with rise in obesity, because, fat has very high energy content, more than twice what is in protein or carbohydrates. Thus a very small meal with high fat is high in energy. Evidence has also shown that fat is less satiating than either carbohydrates or proteins and is highly palatable. Unlike other macronutrients increased fat intake does not increase oxidation but rather increases its storage. (Poppitt et al. 1996).

Learned behavior can also lead to weight gain. Appetite is a psychological behavior that can be enhanced by deep emotional needs such as fear of starving, eating not because one is hungry but because it's the learned time to eat, yearnings, cravings and addictions. Some people eat because they are depressed, others will eat to reduce boredom. All these are psychological not physiological reasons of adding unwanted calories to the body that end up being stored as fat. 
With increased modern technology, physical activity has decreased tremendously. In the past, most work involved muscle power; there were fewer cars available thus people walked more. Today machines do much of the work and people rarely walk. Most of the obese people do not necessarily consume too much, but they do very little energy expenditure that the little eaten is stored as fat. If these people try to reduce the amount eaten, it would jeopardize their health, only increasing physical activity would help with weight control. The Food Guide Pyramid encourages at least 30 minutes a day of physical activity. However to lose extra fat at least 90 minutes is encouraged which include cardio- exercise. Watching TV contributes to obesity, first because it requires very little energy beyond resting metabolic rate and second, it replaces time that would be spent doing a vigorous activity and in most cases people tend to have snacks while watching TV (Vareecken et al, 2005).

Obesity is one of the major causes of cardiovascular diseases (CVD) and there has been associations linking childhood obesity to CVD in adulthood (Freedman et al, 2004). Therefore controlling childhood obesity will reduce incidences of CVD and other heart diseases later in life. Genetics play a role in the development and progression of this disease but it is coupled with other factors that may increase risk. Children, however, most of the times do not make choices of what they eat, parents and guardians do, and therefore these people play a very big role in the health and the future of the children. USDA recommendation for children 2- 8 years includes

- At least 60 minutes of physical activity everyday of the week

- 3 or more ounces equivalent whole grains per day

- 2 cups per day of low fat or fat free milk or milk product. 
- Less than $10 \%$ of calories from saturated fat and less than $300 \mathrm{mg} /$ day cholesterol

- Total fat, 30-35\% of total calorie

- Use of lean meats and poultry

A guide to basic diet modified from Lowenberg ME: Development of food patterns in young children: Nutrition in infancy and childhood, $6^{\text {th }}$ ed., St Louis, 1997 , recommends the following feeding guide for preschoolers:

\section{2 to 3 year olds}

Food

Milk and dairy products

Meat, fish, poultry or equivalent

Fruits:

$\begin{array}{ll}\text { Raw } & 1 / 2-1 \text { small } \\ \text { Canned } & 2-4 \text { tbsp } \\ \text { Juice } & 3-4 \mathrm{oz}\end{array}$

Vegetables

Bread and grain products

\section{Portion size}

$1 / 2 \operatorname{cup}(4 \mathrm{oz})$

1-2 oz

$3-40 z$
Number of servings

4- 5

4-5

$1 / 2-1$ slice of bread 3

$1 / 4-1 / 2$ cup cooked cereal

1/2- 1 cup dry cereal 


\section{4- to 6- year olds}

\section{Food}

Milk and dairy products

Meat, poultry, fish or

equivalent

Vegetables

Fruits:

Raw

Canned

Juice

Bread and grain products
Portion size

$1 / 2-3 / 4$ cup

$1-2 \mathrm{oz}$

3-4 tbsp

4-5

4-5

$1 / 2-1$ small

4-6 tbsp

$4 \mathrm{oz}$

1 slice of bread

3

$1 / 2$ cup cooked cereal

1 cup dry cereal

\section{Number of servings}

\section{3-4}

2 


\section{CHAPTER 2}

\section{LITERATURE REVIEW}

Obesity in children and adolescents is a strong predictor of a broad range of health problems and increased mortality and morbidity in adulthood. In a longitudinal study done on adolescents who were participants in the Harvard growth study of 1922 - 1935, subjects who were obese and overweight adolescents had an increased mortality rate due to disease- specific causes than did the normal weight subjects after over 55 years of follow-up. Risk of morbidity due to coronary heart disease and atherosclerosis was especially elevated (Must et al., 1992). Another health complication that can be predicted by childhood obesity is metabolic syndrome. Srinivasan et al, (2002) carried out the Bogalusa heart study to determine if childhood adiposity was a predictor of development of syndrome $\mathrm{X}$ in adulthood. In the study subjects were between 5- 17 years old children and 19- 38 years old young adults. This was a longitudinal study done between 1978-1996. They found out that children who had a higher BMI at the beginning of the study had a higher prevalence rate of developing syndrome $\mathrm{X},(6.4 \mathrm{vs} 3.6 \% ; \mathrm{p}<0.01)$. It was concluded that BMI was the only predictor of syndrome $\mathrm{X}$ in adulthood in both males and females and in all races.

Genetics plays a key role in obesity occurrence. Parents who are obese have a higher risk of having a child who is obese and children who are obese are more likely to be obese adults. This could be explained by the multiplication of fat cells and by acquired feeding habits the child is exposed to. Having the two factors; obese parents and childhood obesity, puts the person even at a higher risk of obesity. To investigate this hypothesis Whitaker et al, (1997) did a retrospective cohort study on some young adults and their parents. Results of the study concluded that the probability of being an obese adult increased with the age of the obese child 
and after 6 years as an obese child, the probability of adult obesity exceeded $50 \%$, compared to $10 \%$ of non obese children. Obesity at $1-2$ years of age did not correlate with obesity in adulthood. Risk of obesity was significantly higher if either mother or father or both parents were obese. This was more pronounced if the child was less than 10 years old. Below 10 years, both parents' and child's obesity were the predictors of adulthood obesity but above this age child's obesity status was the only predictor of adulthood obesity.

Genetics have been reported to be a major factor in food preferences and taste. Bitter, sour, salty and sweet are known to be innate. However Birch (1979) suggest that though these factors are innate they can be modified over time by environmental factors many of which involve the home and the food a child is constantly exposed to. Early exposure of a child to fruits and vegetables or exposure to high energy foods establishes a hierarchy of that particular food. Studies have shown that young children's exposure to certain food increases their preference for the food. Another similar study by Sullivan and Birch (1990) on infants and their acceptance of new foods produced similar results. The children were introduced to new foods, in a particular flavor, ten exposures over ten days. They reported that the children developed a significant acceptance of the particular food with the particular flavor unlike other foods and other flavors. Parental preferences, beliefs and knowledge are also factors that affect child's dietary intake. A study done by Gibson et al (1998) on 5-11 year old children and their parents showed that the level of children's neophobia was significantly related to the parents' neophobia. In this study mother's nutritional knowledge, frequency of fruits consumption and conviction that increasing fruits and vegetable intake would reduce the risk of developing cancer were found to be independent predictors that a child will consume more of the fruits and vegetables. 
Diet quality is another factor that determines obesity prevalence. The U.S Department of Agriculture (USDA), in an effort to monitor the quality of foods Americans consume came up with a Healthy Eating Index (HEI) which is a broad way of evaluating diet quality based on the adequacy, moderation and variety. This is a score for the consumption of the five major food groups in the Food Guide Pyramid, intake of total fats and saturated fats, cholesterol and sodium. Based on HEI, a study was done on children between ages 2-9 years from 1994 to 1999(Lino et al., 2002). In this study the index is a sum of 10 dietary components equally weighted and can have a maximum of 100 points. Component 1-5 represents the five major food groups, (grains, meats, milk, fruits and vegetables) component 6 measures total fat as a percentage of total caloric energy, component 7 measures saturated fats, component 8 measures cholesterol, component 9 measures sodium and component 10 is the variety of food consumed. HEI score over 80 is considered good, 51- 80 needs improvement and $<51$ means poor diet. People with high HEI were found to have low BMI and those with low HEI were found to have high BMI. The results of the study showed that $81 \%$ of the children had diets that needed improvement and $19 \%$ had a good diet. However, most children met the RDA for many essential nutrients. The children had the greatest score in cholesterol, $82 \%$ met the recommended amount. The lowest score was on the meats, only $18 \%$ met the recommendation, $22 \%$ met the vegetable recommendation, $29 \%$ met the recommendation for saturated fats and 33\% met the recommendation for fruits.

Just like United States, other developed countries have experienced tremendous increase in cases of overweight and obese children. In a study done by Bittman et al(1998) in Australia on the food being consumed in majority of the homes, he found out that expenditure on raw foods has significantly reduced over time while that of reduced- preparation and highconvenience foods have significantly increased. This kind of trend seen in most developed 
countries as the priorities for work outside the home increases and less time left to prepare healthy meals have forced most unhealthy, high processed foods and fast foods in most American's home. Since this is what is available, it is what the children consume all day and due to exposure they develop a preference for them. This causes a trend of unhealthy eating and obesity stays on the rise.

Lack of accurate nutrition knowledge by the caregivers can compromise their weight and that of the children. Klohe-Lehman et.al (2006) studied the influence of mother's knowledge on weight status. They recruited 141 mothers, $21 \%$ were overweight and $79 \%$ were obese, and put them through an intensive training. The aim was to improve the mother's nutritional knowledge and promote weight loss. They underwent 6 months of training in areas of diet, physical activity and behavioral modification. The results showed increased nutritional knowledge and weight loss among the participants. Mothers who had $\geq 2.27 \mathrm{Kg}$ weight loss had gained greater nutritional knowledge than those who lost less weight. Those who gained weight only improved in two areas of the test while those who lost weight gained knowledge in all the six areas of the test.

Thakur et al (1999) did a study to determine if nutrition knowledge was correlated to obesity. The subjects were high school students $9^{\text {th }}-12^{\text {th }}$ grade randomly selected across 3 schools. Two of the schools comprised of low and middle social economic class while the other school comprised mainly middle and upper class students. They found out that there was higher prevalence of obesity among African Americans but no significant differences between gender, site or grade level. There was a general overall poor nutrition knowledge. Most of the respondents reported eating less than 4 meals per week with the family and $67 \%$ of the respondents reported missing breakfast. There was no significant difference between obese and 
non obese subjects on nutrition knowledge but there was a significant difference in identification of high fiber food. Students from higher social economic status had a significant superior nutrition knowledge but there was no difference in the occurrence of obesity in all the schools. Obese students reported eating infrequent meals than their non obese counterparts. This study indicates that regardless of nutrition education offered in schools the students did not practice healthy eating habits.

A study done in London by Gibson et al (1998), on mother's nutritional knowledge and attitude on fruits and vegetables showed a great influence on what the mothers know and what they fed the children. This was done on children between ages 9- 11 years. A questionnaire was prepared of common foods, fruits juices and vegetables to test the mother's knowledge and the mother's education level were noted. The results indicated that mothers who gave more of fruits and fruit juice, fiber and proportional energy intake, had higher level of education. Vegetable and confectionary intakes were not correlated with mother's education level. Also mother's nutritional knowledge strongly correlated to children's fruit intake. On mothers' choice of food, taste was the first factor that influenced choice of food, followed by health and well being, disease prevention and cost.

Klesges et al (1995) did a longitudinal analysis on modifiable factors (dietary intake and physical activity) and non modified factors (age, sex, family history), on preschool children for three years. Children ages 3- 5 years were recruited of which obese ones were over sampled because the aim of the study was to evaluate energy balance. Height and weight measurements were taken and dietary intake was assessed using Willett Food Frequency Questionnaire. Food models were provided to help estimate serving sizes. In the conclusion they suggested that both modifiable and non modifiable factors were associated with increased BMI among preschool 
children with the modifiable factors being more important. Among the non modifiable factors, family history of obesity was a more consistent factor with increased BMI. This was more common in boys than in girls. They suggested that dietary intake and physical activity are independent risk factors for increase in body weight. Percentage dietary fat intake was associated with weight gain but not the total energy intake. They concluded that amount of fat intake is a more risk factor to weight gain than energy intake is. This could be explained by the fact that high fat consumption can lead to overeating because fat has reduced capacity to suppress satiety. To investigate this hypothesis Blundell et al. 1997 did a study to determine the effect of carbohydrates and fats on satiety. Subjects were normal weight individuals and each person was given a breakfast containing 440kcalories. Another group was given the same diet supplemented with fat and the third group was given the same diet but supplemented with carbohydrates. The control group consumed a total of $440 \mathrm{kcalories,} \mathrm{the} \mathrm{high} \mathrm{fat} \mathrm{group} \mathrm{and} \mathrm{the}$ high carbohydrate group consumed $803 \mathrm{kcalories}$ each. Participants were told to rate palatability of the breakfast and motivation to eat. This was done before and after treatment.

The results indicated that the group that had high carbohydrate supplemented breakfast was able to suppress hunger better than the fat supplemented group. This was only significant for a period of 4 hours after breakfast, later than that the difference was not significant. In the same experiments, subjects were given the same breakfast of $440 \mathrm{kcal}$ and allowed to wait 90 minutes. After 90 minutes they were given either a fat supplemented snack or a carbohydrate supplemented snack. Results indicated that the group that took carbohydrate supplemented snack suppressed hunger and appetite more as compared to the fat supplemented group. When this was repeated after 270 minutes there was no significant difference in satiety indicating that 
suppression of appetite was only for a limited time similar to the previous experiment. This experiment was repeated on obese people and results were similar.

Consumption of fats may increase the rate of obesity because fat is considered to be high density food. High density food increases the amount of energy intake even when the actual food consumed by weight is low. Replacing energy dense food with fruits and vegetables will lower the total energy intake. In a study to investigate this principle, Ledikwe et al, 2006 used the data from 1994 - 1996 Continuing Survey of Food Intakes by Individuals (CSFII). This is a 2-day survey done by USDA. This was conducted on 2 non- consecutive days and used multiple pass technique to obtain 24-hr food recalls. It was found out that the participants who consumed low energy dense diet had a lower total energy intake as compared to those who had high energy dense diet. Women who had low energy dense diet had a significantly lower BMI but this was not significant in men. The prevalence of obesity was $6 \%$ lower for the men with a low energy dense diet. Both male and female subjects who consumed diets high in fruits and vegetables consumed less energy from saturated fats. Those with the highest amounts of fruits and vegetables consumed diets with the lowest energy density and had the lowest energy intake and the lowest obesity prevalence. Fat intake in this study was also correlated with increased serum cholesterol and risk of cardiovascular diseases. According to this study, kilocalories from fat should be the primary target for obesity prevention

Birch et al (2004) did a study on family environmental factors that influence childhood obesity. She observed that children's genetic predisposition influence their weight status. These predispositions include food preference for sweet and salty tastes, rejection of bitter and sour taste, and physiological consequences after eating the food. Because much of the availability of food is controlled by the parents, cultural and socioeconomic factors play a role. Also the 
number of times a child is exposed to a new food, the more he will become familiar with it and this increases the likelihood of accepting the food. Therefore if a parent is more persistent on healthy foods, the child is more likely to accept the food, and develop a healthy eating habit. In the study they looked at pressure and coercion placed on children by the parents. They concluded that the more pressure a parent puts on a child to eat some food for instance vegetable, while trying to get a child to eat healthy, the more likely the child will reject the food. They suggested that parents should form a habit of providing variety of all healthy foods on the table and let the children choose, this way they grow to appreciate all the foods. On the other hand, parents keeping away unhealthy snacks only make the children have more of these snacks when available. Pressure and coercion may be driven by the weight status of the child and/or that of the parent. Some parents may fear their obese children growing up to be obese adults, or may fear that the child is at risk of obesity if they are obese themselves. This could affect the child's feeding habits and jeopardize any weight management effort. They suggest that parents should strive to teach children to snack healthy and in moderation. They also supported the idea that children be trained to react to internal feeling of hunger and satiety and not external factors such as having to clear a plate. Children as young as 6 weeks old have been shown to adjust their energy intake every 24 hours. However as they grow up and pressure of external factors are put on them they are no longer able to regulate their energy and they do not eat because of hunger but due to availability.

Constanzo and Woody (1985) suggested that parenting styles differ. Parents who are more likely to exert good feeding habits are those concerned with the child's development and child's weight issues. Also those parents who believe a child to be at high risk of obesity, and those who do not believe that the child has control over eating are likely to exert feeding control. 
In their study the child feeding questionnaire assessed parents' attitudes, beliefs and tendency to use control in feeding and concerns of weight status. They noted that parents with heavier children exerted more control in what the child ate and these children showed less ability to adjust their caloric intake in the absence of control. Johnson and Birch (1994) did the same kind of study and had similar results. In their study they concluded that parents' inclination to use control was due to three factors, (i) parental concern about the child's weight (ii) perceived child weight (iii) perceived parent weight. On a similar study done by Birch and Deysher (1986) and Birch et al (1984) pressuring children to eat healthy foods decreased the children's preference for those foods. Also restricting the children from eating "junk" food increased the intake of those foods when monitoring was removed.

Caloric compensation involves adjusting amount of food consumed depending on the density of food. Excess energy intake should be followed by reduced intake in the next meal. Failure to compensate leads to a positive energy balance and tendency to add weight. To determine caloric compensation, Lissner et al (1987) gave 24 women diets with varying fat content for 47 days. They were given low, medium and high fat diets. Only the provided foods and beverages were consumed during the entire period. To compensate for vitamin and mineral intake supplements were provided. Results showed that energy consumption correlated positively with fat consumption. The subjects did not display any caloric adaptation in the experiment period. This is unlike other studies on regulation using carbohydrate manipulation where caloric regulation and compensation has been observed. Body weight increased with increased caloric and fat intake. Weight gain was even higher in the overweight subjects than the lean subjects indicating that overweight people may not be able to regulate caloric intake as efficient as lean people. 
Children just like adults are not able to regulate their energy; they eat what is served to them. Gordana and his colleagues(2005) did a study on 4- 6 year old children in two daycare centers in New York. The children were served regular diet at home and in the daycare center and their caretakers completed a 24-hr dietary intake questionnaire for 5-7 consecutive days. The children were allowed to reject what they did not want to eat and have more of what they liked. Three snacks in a day were provided for any child who wanted. In the daycare center, food was weighed before consumption and any spillage noted for adjustments. Food consumed at home was reported by the parents in estimates of standard home measures. Any recipes used and original food wrappings or labels of food at home and daycare centers were collected. This helped in calculating nutrient composition and energy content using a nutrition software. Results of the study showed no significant difference between intakes in the two daycare centers. All the children ate all the three meals in a day but majority did not consume the snacks, however there was a significant difference between amount of snack consumed during weekdays and weekends. More children consumed snacks on weekdays than on weekends. Dinners constituted the largest meal and afternoon snack the smallest meal consumed. There was a strong positive correlation between amount of food served and the amount consumed. Using regression analysis the largest predictor of amount consumed was amount served. Carbohydrate content accounted for $10 \%$ of variance while protein and fat accounted for less than $2 \%$ of variance in the study. There was a significant negative correlation between amount of food consumed in 2 consecutive meals; and this applied also to amount served at two successive meals. Children ate more food when the energy density was low than when high but this was indicated to be imprecise after adjusting for the amount served. When the children consumed their snacks they took in $40 \%$ more food and $30 \%$ more energy than when they did not consume all the snacks. This study demonstrates that 
children are not able to regulate their energy intake; rather the amounts consumed depend on the amounts served.

To investigate parental perception on child's weight, Myers et al (2000) administered a questionnaire to 200 parents of obese children. They observed that $43 \%$ of parents thought that their child's weight was okay, $72 \%$ stated that they believed that an obese child could develop cardiovascular problems later in life, 53\% denied that they had a problem controlling what the child ate and $35.5 \%$ did not believe that their child was overweight. They concluded that for an intervention to be productive, the initial stage should be to recognize the beliefs and perceptions of the parents as this has a great impact on nutrition practices they implement in their children.

Parental perceptions affect feeding practices and so influence the weight of children. Preschool children are most likely to be affected by parental feeding habits because they rely mainly on what is given to them by their guardians. This is also affected by cultural beliefs and practice as well as social economic status. Baughcum et al, (2000) carried out a study in which 622 mothers of 23- 60 month old children were given a questionnaire to assess maternal feeding habits. The questions targeted both the perception of child's weight and mother's weight. Data on family income, level of education, family size and maternal smoking was obtained. Mother's weight and height was obtained by self reporting while that of the children was measured on site. Participants were obtained from two sites; 55\% were recruited from a WIC program in a Kentucky clinic and were considered to be of low SES while $45 \%$ were recruited from a Cincinnati Pediatric Research Group (CPRG) whose medium income ranged from $\$ 60,000$ 69,000 per year and so considered of high SES. Results of the study indicated that obesity was more prevalent among the WIC group and also among the mothers with low levels of education. Obesity was also more prevalent among the non white mothers than the whites. Most mothers 
had the actual perception of their children's weight but some were not accurate of their own weight. Perception did not differ between different education levels. Among mothers with obese children, only $21 \%$ had the right perception of their children's weight while among those whose children were overweight, only $29 \%$ perceived their children to be overweight. This was also significantly correlated to education level. Mothers with low education level were more likely to have the wrong perception as compared to those with higher education. Mothers who had overweight and obese children and had the right perception were more likely to be worried about their children's weight than those who had wrong weight perception.

Fisher et al. 1995, assessed if high fat preference is associated with high fat intake and adiposity both in children between ages 3 to 5 and in their parents. The results of this study showed that children's fat intake ranged from $25 \%$ to $41 \%$ of energy as dietary fat. Children who had high fat preference consumed high percentage of total energy as dietary fat which was related to high adiposity. The children's fat preference was positively correlated to the parent's adiposity. In a similar study by Gazzaniga and Burns (1993), on children ages 9 to 11 years, total fat intake and saturated fat intake was strongly correlated to the adiposity of the children.

Obesity has further been compounded by the fact that children engage in less physical activities than they used to before because of increased access to entertainment electronics. A lot of free time is spent watching TV and playing computer/ video games. Most often they will tend to snack on fatty foods and drink soft drinks which increase energy intake and replace healthier food consumption. The American Society of Pediatrics recommends not more than 1-2 hours of quality TV viewing per day and discourage the presence of TV sets in the kids bedrooms. Many studies have been done to investigate any relationship between TV viewing and adiposity. In one of the studies, Vareecken et al., 2005 conducted a study across Europe, USA, Canada and Israel. 
The study was conducted in the form of questionnaire in which TV viewing, eating habits and social economic status were some of the variables measured. The subjects were 11-15 year old adolescents. They found out that boys and children from low SES had a tendency of watching more TV and playing computer games. Those that reported more viewing hours consumed more sweets and soft drinks. Utter et al, 2005, conducted a study in New Zealand to investigate time spent watching television and food consumption. The subjects ranged from 5years to 14 years grouped in two; children 5-10 years and adolescents $11-14$ years. They found that $30 \%$ of the children and $40 \%$ of the adolescents watched TV more than 2 hours per day. TV watching was strongly associated with SES of the children but not of the adolescents. There was no significant association between television watching and obesity but there was a significant positive association between television hours and consumption of soft drinks, humburgers and frenchfries. In the adolescent group there was a significant positive association between television watching and consumption of regularly advertised foods. In both groups there was no significant relationship between TV watching and consumption of fruits, vegetables, milk, potato chips, biscuits, fruit drinks and fried chicken. When the whole sample was analysed (5-14 years) there was a positive correlation between TV watching and consumption of chocolate sweets, soft drinks, fruit drinks, potato crisps, biscuits, humburgers and French fries, and a negative association between television viewing and fruits and vegetable consumption.

A study by Giammattes et al, (2003) looked at 11- 13 year old school children and their TV watching and soft drink consumption trends and how this influences their weight. Subjects weight and height was measured on site and a questionnaire was administered which included how many hours they spent watching TV or playing computer or video games. Any kind of sport activity a child was engaged in was also noted including the frequency of participation. The 
subjects also reported the number of regular or diet soft drinks and sugar sweetened beverages consumed in a day. Also reported was who prepared their meals and where they ate their meals each day. Of the sample used, $17.9 \%$ were overweight and $17.4 \%$ were obese. There was no significant difference in the BMI of boys and girls but girls had a higher percent fat mass than boys. Out of the variables measured only the hours spent watching television and number of soft drinks consumed correlated significantly with the weight. Those who watched more than 2 hours of TV had $4.9 \%$ more body fat and were $79.9 \%$ more likely to be overweight. Those who consumed 3 or more soft drinks in a day had a BMI z-score 0.51 higher and $4.4 \%$ more body fat. Hispanic children watched more television and consumed more soft drinks than non Hispanics. Amount of soft drinks consumed was positively correlated to hours spent watching television.

From previous studies, obesity is a multifactor epidemic. To be able to get an intervention, it is important to find out which of the above studied factors have the greatest impact, or are stronger predictors of obesity in rural West Virginia. A pilot study was designed to investigate familial and environmental factors that contributed to overweight among a group of preschool children in rural West Virginia. 


\section{OBJECTIVES OF THE STUDY}

This study will focus on how diet, familial and environmental factors are related to obesity occurrence. We will therefore be looking at the correlation between the following factors;

- Parent's nutritional knowledge and child's BMI.

- Parent's level of education and parental nutritional knowledge.

- Parent's level of education and child's BMI

- Parent's perception and child's BMI.

- Parent's perception and parent's control

- Parents control and child's BMI.

- Diet quality and BMI.

- Servings of high fat food and BMI

- Servings of high sugar food and BMI

- $\quad$ Presence of TV in the room and BMI.

- Number of screen time hours and BMI 


\section{CHAPTER 3}

\section{METHODS}

This study was done in Mercer and McDowell counties, in rural West Virginia. Extension officers recruited children aged 2-5 years participating in Family Nutrition Program in Head Start. The investigators met with the parents prior to enrollment to explain and answer any questions. Study was approved by the West Virginia Institutional Review Board for the protection of human subjects and all parents gave a written consent for their children to participate (Appendix A).

The children were weighed with an electronic scale and height taken with a standard portable stadiometer. BMI was calculated using the formula weight $(\mathrm{kg}) / \mathrm{height}\left(\mathrm{m}^{2}\right)$. Height for the age percentile and z score and weight for height percentile and corresponding $\mathrm{z}$ score and BMI percentile and z score were calculated using epi info 2000( CDC, Atlanta, GA, 2000). Children whose BMI was at or above $95^{\text {th }}$ percentile were considered to be overweight. Those with BMI between $85^{\text {th }}$ to $95^{\text {th }}$ percentiles were considered to be at risk of being overweight. Children below the $5^{\text {th }}$ percentile or with a $\mathrm{z}$ score less than -2 were considered underweight. Between the $5^{\text {th }}$ percentile and $85^{\text {th }}$ percentile was considered normal.

The subjects were divided into 3 groups depending on the BMI percentiles; group 1, 2 and 3 for normal weight, at risk of being overweight and overweight respectively. The mean for each group on the following variables was calculated; weight for age percentile (WAP), weight for age z score (WAZ), height for age percentile (HAP), height for age z score (HAZ) and weight for height percentile (WHP). Mean BMI percentile and BMI z-scores of the children were calculated and mean BMI of both parents were also computed. 
Parents and caregivers were given a questionnaire packet. This packet was divided into six sections. The first section had questions about child's demographic information (Appendix B). The second section was on parents/caregiver information (Appendix C). This included demographics (weight and height of parents was by self reporting), level of education, how many hours worked, who is responsible for buying food and who most often prepared family meals. Also included was presence or absence of TV in the child's room and how many hours a child spent watching TV or playing computer games. The third section was a test on nutrition knowledge (Appendix D). Basic nutrition knowledge questions were asked and the parents/ caregiver answered and the score noted out of maximum thirty points. The fourth part comprised of a feeding habit section (Appendix E). This was a total of thirty questions asking about the feeding attitudes and beliefs, feeding control habits, perceptions of child's weight and fear of the child gaining weight. The fifth section asked about food insecurities. Parents were asked if they were able to obtain the foods they wanted or if cost was a limiting factor. The sixth section was a 24-hr food recall. Each section was analysed independently depending on the variable being tested and relationships between factors of interest were analysed.

Fisher's test analysis was done to calculate the differences between groups 1,2 and 3 in the following variables; mother's and father's BMI, age and education. Each of the variables was analysed in both male and female subjects. A similar test was done to calculate any differences in percentiles between the gender and among ethnicities. A correlation analysis in each of the following variables was done; parent's nutrition knowledge, mother's and father's education level, parental control, food quality, sugar and fat content in the food and hours spent watching television. A logistic regression analysis was done on presence of TV in the room and weight perception. BMI z-score was the dependent variable in all the above analysis. A multiple 
regression analysis was then done to all the above mentioned variables to determine which of the variables were the best predictors of obesity in this population. 


\section{SAMPLING AND HYPOTHESES}

\section{Parental nutrition knowledge}

Hypothesis; There is a negative correlation. Higher parental nutrition knowledge score is less likely to be associated with child's BMI $\geq 85^{\text {th }}$ percentile.

To asses this relationship between the parent's nutritional knowledge and the child's BMI, a total of thirty questions were given, all of which tested different aspects of nutrition knowledge. The answers were summed up out of thirty. The higher the total points scored the better the parent was considered in terms of nutritional knowledge. This was then compared to the BMI $\mathrm{z}$ score of the children and a correlation, if any was determined.

\section{Level of education as compared to nutrition knowledge}

Hypothesis; There is a positive correlation. The higher the level of education the better is the nutrition knowledge.

Both fathers and mothers education level was analysed independently. Level of education was divided into five categories. Less than 12 years was assigned numeral 1 , high school diploma or equivalent was assigned 2, some college courses 3, college degree 4 and graduate degree 5. This was then compared with the total scores obtained in the nutrition knowledge questionnaire. The level of education was then compared with the child's BMI zscore. It is expected that the higher the level of education the less likely BMI will be $\geq 85^{\text {th }}$ percentile. 


\section{Weight perception as compared to the actual BMI z-score}

Hypothesis; Parents whose children are overweight perceive their children to have normal weight range. There is a negative correlation.

To test this hypothesis, question \# 10 in the child feeding questionnaire (appendix E) was used. The question asked what the parent best describes the child as a preschooler. The correct answer was determined by the BMI percentile of the child. For this study below $95^{\text {th }}$ percentile or \#1 and 2 was considered normal, in order to avoid confusion on borderline children. If a child had a BMI $>95^{\text {th }}$ percentile or \# 3 , and the mother answered that the child was normal which was answer choice 3 , the score was a zero. If the same mother answered overweight or markedly overweight, answer choice 4 or 5 , the score was 1 . This was compared with the BMI z-score. A logistic regression analysis was used because of dichotomous dependent variables, meaning that there were only two possible scores, zero or one.

\section{Parent's perception of child's weight and parental control}

Hypothesis; Parents will exert more food control if they perceive the child to be overweight or is at risk of being overweight.

To determine the relationship between the parental perception and how much the parents controlled the food a child consumed, questions \# 2, 3, 14, 15, 17, 22, 24, 26, 27, and 28 were considered. The answers were numbered 1 through 5, 1, indicating lowest control and 5 indicating the highest control. The highest possible points were fifty, which translated to the highest control level. For perception, question \# 10 was used, which was scored one through five, one being the lowest weight and five the highest weight. 


\section{Parental control and BMI z-score}

Hypothesis; There is a positive correlation. Increased parental control leads to increased BMI.

For this analysis I used parental control questions \# 2, 3, 14, 15, 17, 22, 24, 26, 27, 28. Each question was scored one through five, five being the highest control level and the highest possible score being fifty. BMI was classified as 1,2 and 3, 1 being normal, 2 at risk of being overweight and 3 as overweight.

\section{Food quality and BMI z-score}

Hypothesis; There is a negative correlation. Children who did not get all the five classes of food groups had increased BMI.

For this study I considered the presence of five major classes of food, that is, Grains, meats, milk, fruits and vegetables, in the 24-hour food recall. Availability of each class was assigned one point with a total of five points. Sample size was $n=160$. The total points versus the BMI z-score were analyzed. The percentage number of children who consumed all the five food classes was calculated. Also calculated was the percentage number of children who did not consume at least one fruit per day and those who did not consume at least one vegetable serving a day.

\section{High fat and high sugar foods as compared to BMI}

Hypothesis; High fat and high sugar foods contribute to high BMI.

In this analysis I considered high fat food as all fried foods, fast foods and food with at least $20 \mathrm{~g}$ of fat per serving size (Krause,2004,). For high sugar foods I considered all sweetened 
drinks and soft drinks except for diet sodas. Both fat and sugar were analyzed independently and as a combination. Percentage number of children who did not take any fast food in that day and those who did not drink any high sugar drink in that day was calculated.

\section{Presence of TV in the room}

Hypothesis; Presence of TV in the room predicts a high BMI.

Presence or absence of the TV in the child's room was entered as one for presence and zero for absence. This was then compared with the BMI. A logical regression analysis was used because there were only two possible scores, zero or one. A correlation analysis was done on hours spent watching TV and/or playing video games with BMI z-scores. 


\section{CHAPTER 4}

\section{RESULTS}

The sample used was composed of 203 children ranging from 25.6 months to 77.9 months and the average age was 52.23 months. There were 94 boys, 108 girls of which 182 were whites and 21 were blacks. Mothers' average BMI was 27.98 and the fathers' was 28.13 (table 1). Most of the parents had at least a high school diploma. Results also indicated that most of the household food purchase and preparation was done by mothers and on average fathers worked more hours.

\section{Table 1: Description of sample population}

\begin{tabular}{lcc} 
Variable & Average & SD \\
\hline Age (months) & 52.23 & 10.44 \\
Height (inches) & 40.47 & 3.23 \\
Weight (lb) & 41.21 & 9.96 \\
Child BMI percentile & 63.25 & 2.55 \\
Child BMI z-score & 0.521 & 1.13 \\
Mothers' BMI & 27.98 & 7.55 \\
Fathers' BMI & 28.13 & 5.60 \\
Mothers' working hrs/week & 34.95 & 9.68 \\
Fathers' working hrs/week & 43.16 & 8.02 \\
\hline
\end{tabular}

Subjects were divided into three groups depending on their BMI percentiles, group 1,2 and 3 for normal weight (BMI $<85^{\text {th }}$ percentile), at risk of overweight (BMI $85^{\text {th }}-95^{\text {th }}$ percentile) and overweight (BMI $>95^{\text {th }}$ percentile) respectively. The mean of each group on the following variables was calculated; weight for age percentile (WAP), weight for age z-score (WAZ), height for age percentile (HAP) height for age z-score (HAZ) and weight for height percentile (WHP). 
Table 2: Mean groupings

\begin{tabular}{|c|c|c|c|c|c|c|c|}
\hline Percentile & $\mathrm{n}$ & $\%$ & WAP & WAZ & HAP & HAZ & WHP \\
\hline 3 (BMI>95th) & 39 & 19.2 & 92.843 & 2.735 & 67.22 & 0.6613 & 97.223 \\
\hline $\begin{array}{c}2 \text { (BMI }=85 \text { th }- \\
95 \text { th })\end{array}$ & 31 & 15.3 & 79.863 & 1.0619 & 59.162 & 0.369 & 87.738 \\
\hline $\begin{array}{c}1 \text { (BMI= 5th- } \\
85 \text { th) }\end{array}$ & 133 & 65.5 & 42.333 & -0.2723 & 44.102 & -0.1914 & 46.429 \\
\hline & $\begin{array}{l}\text { WAP- w } \\
\text { WAZ- we } \\
\text { HAP- he } \\
\text { HAZ- he } \\
\text { WHP- w }\end{array}$ & $\begin{array}{l}\text { age p€ } \\
\text { age } z- \\
\text { age pe } \\
\text { age } z- \\
\text { height }\end{array}$ & & & & & \\
\hline
\end{tabular}

Fisher test was used to calculate the differences among groups in the following variables; mother's and father's BMI, mother's and father's age and mother's and father's education. Each of the variables was tested in both male and female children. A similar test was done to calculate any differences in percentiles between the gender and among ethnicities. Results are indicated in table 3.

There was a significant association between mother's BMI and the BMI of both boys ( $\mathrm{p}=$ $0.0205)$ and girls $(\mathrm{p}=0.034)$, (table 3$)$.There was a significant relationship between fathers' BMI and the girls BMI ( $\mathrm{p}=0.021)$ (table 3$)$ but the association was not significant in boys. There was also a significant relationship between fathers' education and the boys weight $(\mathrm{p}=0.0218)$ (table 3). There was a significant difference in percentile distribution between genders $(\mathrm{p}<0.01)$ (table 4) but no significant difference among different ethnic groups (table5). 
Table 3: Fisher's test for differences in percentile distribution

\begin{tabular}{lcll} 
Variable & Gender & $\mathbf{N}$ & $\mathbf{p}$ - value \\
\hline Mother's BMI & 1 & 94 & $0.0205^{*}$ \\
Mother's BMI & 2 & 109 & $0.0304^{*}$ \\
Father's BMI & 1 & 94 & 0.6496 \\
Father's BMI & 2 & 109 & $0.021^{*}$ \\
Mother's age & 1 & 89 & 0.1759 \\
Mother's age & 2 & 103 & 0.8265 \\
Father's age & 1 & 84 & 0.3916 \\
Father's age & 2 & 94 & 0.3275 \\
Mother's education & 1 & 90 & 0.1056 \\
Mother's education & 2 & 106 & 0.0952 \\
Father's education & 1 & 83 & $0.0218^{*}$ \\
Father's education & 2 & 94 & 0.2289 \\
\hline \multicolumn{2}{c}{ * Significant relationship (p<0.05) } \\
1= boys \\
2= girls
\end{tabular}

Table 4: Test for differences in percentile distribution between genders

\begin{tabular}{|l|r|r|l|}
\hline Gender & N & $\begin{array}{l}\text { Mean BMI } \\
\text { percentile }\end{array}$ & $\begin{array}{l}\text { Mean } \\
\text { BMI z- } \\
\text { score }\end{array}$ \\
\hline Boys & 94 & 61.57 & 0.492 \\
\hline Girls & 108 & 64.69 & 0.546 \\
\hline
\end{tabular}

$\mathrm{P}<0.001$ 
A correlation analysis was done on several interrelated variables and results are shown in the table below;

\section{Table 5: Correlation analysis}

\begin{tabular}{|c|c|c|c|}
\hline Variable & r-value & p-value & $\mathbf{N}$ \\
\hline Parents' nutrition knowledge and child BMI z-score & 0.067 & 0.379 & 176 \\
\hline Mother's education and nutrition knowledge & 0.06 & 0.434 & 170 \\
\hline Mother's education and child BMI z-score & 0.034 & 0.72 & 116 \\
\hline Father's education and child BMI z-score & 0.183 & $0.024 *$ & 116 \\
\hline Parents' perception and child BMI z-score & -0.512 & $<0.0001 *$ & 178 \\
\hline Parents' perception and parents' control & -0.056 & 0.553 & 116 \\
\hline Parents' control and child BMI z-score & -0.021 & 0.784 & 166 \\
\hline Food quality and child BMI z-score & -0.029 & 0.715 & 160 \\
\hline High fat food and child BMI z-score & -0.054 & 0.497 & 158 \\
\hline High sugar food and child BMI z-score & -0.129 & 0.104 & 160 \\
\hline TV in the room and child BMI z-score & 0.125 & 0.0794 & 200 \\
\hline Parents' nutrition knowledge and food quality & -0.043 & 0.595 & 158 \\
\hline Nutrition knowledge and fat content & -0.051 & 0.585 & 116 \\
\hline Nutrition knowledge and sugar content & -0.022 & 0.814 & 116 \\
\hline Nutritional knowledge and food quality & -0.066 & 0.481 & 116 \\
\hline Father's education and parent's control & -0.159 & $0.044 *$ & 116 \\
\hline Father's education and parent's perception & -0.193 & $0.019 *$ & 116 \\
\hline Parents' perception and TV in child's room & -0.195 & $0.018^{*}$ & 116 \\
\hline Food quality and control & 0.163 & $0.040 *$ & 116 \\
\hline High fat food consumed and TV in the room & 0.165 & $0.038^{*}$ & 116 \\
\hline Parents working hours and child BMI & -0.02 & 0.977 & 146 \\
\hline TV hours and child BMI & -0.054 & 0.448 & 201 \\
\hline
\end{tabular}

$*$ Significant correlation $(\mathrm{p}<0.05)$

r-value: correlation coefficient.

There was a significant positive correlation between parents perception and BMI z-score $(\mathrm{r}=0.512, \mathrm{p}<0.0001)($ table 5$)$, and a significant positive correlation between father's education 
level and BMI $z$-score $(r=0.183, p=0.024)$. The strongest correlation value was that of parents perception and BMI z-score $(\mathrm{r}=0.512)$. Perception was measured by asking how the parent perceived the weight of the child. The answers were in Likert scale and depending on BMI of the child, if a parent answer was correct, one point was assigned and if the answer was wrong, no point was awarded. Also relatively strong relationships were father's education level and z-score $(\mathrm{r}=0.183)$, high sugar content and $\mathrm{z}$-score $(\mathrm{r}=-0.129)$ and presence of $\mathrm{TV}$ in the room $(\mathrm{r}=$ 0.125) (table 5) and a borderline significance $(\mathrm{p}=0.0794)$.

There was a significant negative relationship between father's education and level of control, between father's education and perception, between parent's perception and presence of TV in the room. Significant positive correlations were found between food quality and control and fat consumed and presence of TV in the room.

A multiple regression was then done on all the above mentioned variables to determine which of the variables best predicts BMI z-score. The regression model was significant, F (9, $106)=4.946, \mathrm{P}<0.0001$, that predicted $23.6 \%$ of variability in BMI z-score.

\section{Regression analysis}

Table 6: Model Summary

\begin{tabular}{|c|c|c|c|c|}
\hline Model & $\mathrm{R}$ & R Square & $\begin{array}{c}\text { Adjusted R } \\
\text { Square }\end{array}$ & $\begin{array}{c}\text { Std. Error of the } \\
\text { Estimate }\end{array}$ \\
\hline 1 & $0.544(\mathrm{a})$ & 0.296 & 0.236 & 1.26572 \\
\hline
\end{tabular}

(a) Predictors: (Constant), TV, food, f.edu, sugar, fat, nutrition .knowledge, control, perception, mother's education Dependent variable: BMI z-score 
Table 7: ANOVA

\begin{tabular}{|l|l|c|c|c|c|c|}
\hline Model & & $\begin{array}{c}\text { Sum of } \\
\text { Squares }\end{array}$ & Df & Mean Square & F & Sig. \\
\hline 1 & Regression & 71.316 & 9 & 7.924 & 4.946 & 0.000 \\
& Residual & 169.817 & 106 & 1.602 & & \\
& Total & 241.134 & 115 & & & \\
\hline
\end{tabular}

Predictors: (Constant), TV, food, f.edu, sugar, fat, nutrition knowledge, control, perception, mother's education Dependent Variable: z-score

Table 8: Coefficients

\begin{tabular}{|c|c|c|c|c|c|c|}
\hline \multirow{2}{*}{ Model } & & \multicolumn{2}{|c|}{$\begin{array}{c}\text { Unstandardized } \\
\text { Coefficients }\end{array}$} & $\begin{array}{c}\text { Standardized } \\
\text { Coefficients }\end{array}$ & & \\
\cline { 3 - 5 } & & B & Std. Error & Beta & $\mathrm{t}$ & Sig. \\
\hline & (Constant) & 1.979 & 1.085 & & 1.824 & 0.071 \\
& nutr.know & 0.015 & 0.020 & 0.066 & 0.777 & 0.439 \\
& m.ed & -0.059 & 0.129 & -0.043 & -0.460 & 0.647 \\
& f.edu & 0.142 & 0.156 & 0.089 & 0.909 & 0.365 \\
& Perc & -1.949 & 0.347 & -0.489 & -5.618 & $0.000^{*}$ \\
& Food & 0.069 & 0.140 & 0.041 & 0.493 & 0.623 \\
& Control & -0.011 & 0.020 & -0.049 & -0.576 & 0.566 \\
& Fat & -0.014 & 0.108 & -0.011 & -0.128 & 0.898 \\
& Sugar & -0.129 & 0.119 & -0.090 & -1.081 & 0.282 \\
& Tv & 0.205 & 0.258 & 0.069 & 0.792 & 0.430 \\
\hline
\end{tabular}

Predictors: (Constant), TV, food, f.edu, sugar, fat, nutrition knowledge, control, perception, mother's education Dependent Variable: z-score

* significant coefficient $(\mathrm{p}<0.05)$

In the multiple regression analysis adjusted $\mathrm{R}$ square for the model was $23.6 \%$ (table 6).

All the variables were entered simultaneously and none was removed (enter method). The variable with the highest Beta (standardized regression coefficient) value was parents perception, Beta $=-0.489$ (table 8$)$ followed by sugar content, Beta $=-0.09$ (table 8$)$ and followed closely by father's education, Beta $=0.089$ (table 8$)$. The model of analysis was significant $\left(\mathrm{F}_{9,106}=4.946\right.$, $\mathrm{p}<0.0001$ ), (table 7). The only significant independent variable was parent's perception (beta= $0.489, \mathrm{p}<0.0001)$, (table 8). 


\section{CHAPTER 5}

\section{DISCUSSION}

In this population food quality was considered low since only $26.1 \%$ of the total sample consumed at least one serving of all the five major food groups and over $50 \%$ of the subjects reported consuming one fruit and one vegetable per day. On average a child consumed only 3 out of the 5 classes of major food groups. The sample used for this study composed of Head-Start children. This is a low income population, and this could be the reason why even with high nutrition knowledge scores, the food quality was low and z-scores high. There was a negative correlation, though not significant, between parents' nutrition knowledge and food quality. This is unlike most studies on nutrition knowledge, education level and food quality. Gibson et al (1998) found a significant positive relationship between mothers' nutrition knowledge and food quality given to children 9-11 years old and a positive correlation between mother's education level and food quality. These results may be indicative that the parents have the right nutrition knowledge but cannot afford a healthy diet. This is further compounded by the fact that the counties that were sampled are quite poor. Low income families are more prone to obesity than high income families according to most studies. In one study done by Baughcum et al (2000), children from a WIC program in Kentucky were more obese than those from a higher SES from Cincinnati. This could be explained by the fact that in limited economic resources, parents seek energy dense food that are high in fats and sugars regardless of nutrient content. They may not afford fruits and vegetables which may predispose the children to weight gain. Also according to Healthy Eating Index (HEI) studies food quality improves with increased income (Bowman et al 1998). In the present study, more parents working hours was correlated to lower BMI, though it was not significant. Those who worked more hours might have more income, thus higher SES. 
Studies have indicated negative correlations between economic status and BMI, which is similar in this study.

Some other studies have reached different conclusions. When studying nutrition knowledge and different social economic status, Thakur et al, (1999) concluded that though students from higher SES had superior nutrition knowledge, there was no significant difference in obesity prevalence between low and high SES groups. It can be concluded therefore that even if most people have the right nutrition knowledge, they do not practice healthy eating habits.

Perception was negatively and significantly associated to BMI z-score and was the strongest predictor of obesity in the regression analysis. A negative correlation means that the parents who had the right perception of their child's weight had normal weight children, and those who had the wrong perception had overweight and obese children. Those parents whose perception was wrong exerted more food control (negative correlation) and the children BMI zscores were higher. Only $26.5 \%$ of the parents had the accurate weight perception of their children. Etelson et al (2003) had similar results where parents with obese children exhibited the lowest accuracy when asked what they perceived their children's weight was. Brener et al (2004) indicated similar results, in which over $22.7 \%$ of the overweight adolescents perceived themselves as being underweight. Maynard et al (2003), in a study on maternal perception of weight status of children reported that $32.1 \%$ of mothers reported that their overweight children had normal weight. On a similar study, Baughcum et al (2000) reported that $79 \%$ of mothers failed to perceive their overweight children to be overweight.

The right perception was correlated with less food control. Parents of obese children tend to be more controlling and this makes the children unable to adjust their caloric intake when the control is removed, this leads to overeating. Birch et al (2004) concluded that control and 
coercion results in children rejecting the food. This usually occurs when parents put pressure for children to eat their vegetables and as a result children learn to reject the food. They also found that keeping away snacks from children just makes them eat more when these snacks are available or when the children grow up and parents are no longer there to control availability of snacks. According to their study, control is more common among overweight parents or those whose children are overweight and obese. Constanzo and Woody (1985) had similar results. They suggested that parents with overweight and obese children should aim at moderation and healthy choices without exerting pressure and coercion as this only leads to children not being able to regulate energy intake and just worsen their weight status.

Education level and z-score was hypothesized to be inversely related. In this study BMI Z-score was negatively correlated to perception implying that parents whose children were overweight and obese had the wrong perception.

In this study fathers had more impact on the diet and the weight of the children than the mothers. Higher education level in both parents was correlated with higher BMI z-score and this was significant with father's education. Higher education would be expected to be correlated with low z-score and healthier weight. This could be explained by lack of resources to provide healthy diet to the children. Father's influence was also portrayed in a study on children growth in rural Kentucky. Father's education was positively correlated to their weight but mother's education was not (Crooks D., 1999). This may imply that the parents have better understanding of nutrition but other factors might be causing them not to feed the right food in the right amount to the children. Considering that these are poor counties and the sample is composed of Head Start children, which means low income families, the economic status might be limiting the parents from accessing good quality food. This can further be supported by the results that higher 
level of education does not translate to high quality food (negative correlation). Cook et al (2006) in their study on food insecurity concluded that, even without measurable hunger, household food insecurity is related to adverse health effects on the children, such as low quality food. Other studies have shown that children from food insecure households are more likely to be overweight and obese (Martin et al 2007). A study done in rural Appalachia by Demerath et al (2003) showed increased prevalence of overweight and obesity among rural economically disadvantaged children.

There was a very high intake level of soft drinks and sugar sweetened beverages; $88.2 \%$ of the children reported consuming at least one such drink in a day. There was an inverse relationship between sugar and BMI. This has been reported in some studies while other studies report positive correlation. This could be as a result of under reporting sugar consumption similar to a study by Hill and Prentice (1995). Overby et al (2003) did a study on effect of added sugar on 4 year olds and 13 year old children. In their study there was a negative correlation between sugar consumption and BMI among 13 year old girls and a borderline significant negative correlation among the 4 year olds. Kvaavik et al (2004) did not find any association between long term sugar intake and weight.

Presence of TV in the room was positively correlated to high BMI z-scores which might indicate low level of physical activity and snacking while watching TV, since high fat consumption was positively correlated to presence of TV in the room. In this study, amount of fat consumed was positively correlated to presence of TV in the room. This relationship was significant. This is similar to a study done by Vareecken et al., 2005, where they concluded that there is an association between TV viewing hours and healthy food consumption. In their studies the subjects that had more TV and computer/ video games hours reported consuming more 
sweets and soft drinks than those who had fewer hours. In their study, low SES was associated with more TV watching. Related to this was a study done in New Zealand by Utter et al, 2005 whereby they found a significant association between the time spent watching television and amount of soft drinks, snacks and fast food consumed, and a negative association between TV viewing and fruits and vegetable consumption.

TV viewing is associated with increased sedentary lifestyle which could lead to weight gain. In a longitudinal study done by Jago et al, (2005) on 3- 7 year old children they concluded that time spent watching TV and level of physical activity are good predictors of obesity. In this study they observed that 6-7 years of age is a critical period that TV viewing affects the physical activity level. There was a strong positive association between TV viewing and BMI and a negative association between BMI and physical activity.

Increased level of father's education was correlated to decreased level of food control and the probability of having the wrong perception of the child's weight. Parents who had the right perception of children's weight had a lower probability of allowing TV in the children's rooms. The higher the food quality the higher was the control, but heavier children had more controlling parents, this could be due to the parents having the right understanding of their children's weight and giving them a healthier diet but being overly controlling. A lot of control has been linked to increased BMI due to children not being able to regulate their energy intake when the control is removed. The other reason for this relationship could be due to underreporting the presumed 'bad' food and over reporting the 'good' food as previous studies have suggested.

In this study $91.3 \%$ of the children consumed at least one serving of fried / fast food or foods considered to contain more than $20 \mathrm{~g}$ of fat, but there was no significant correlation 
between servings of high fat foods and BMI z-score. Dietary fat has been linked to increased obesity because of the energy density in fats. However in this study the method used to evaluate fat content may have not been conclusive. The results rely on self reports from the parents who may under report some food perceived to be bad and over report on those foods perceived to be good. Under reporting could lead to no associations or wrong associations. Poppitt et al (1996) did a study on both obese and non obese women on food reporting. They concluded that there was evidence of under reporting snacks and high carbohydrate foods and there was no bias in reporting proteins and fats. Lafay et al (2000) also found out that under reporting is in three categories; under reporting of specific foods, under reporting of portion sizes and under reporting the snacks. Foods that were under reported mostly were carbohydrates and cheeses. Goris et al (2000) also found significant evidence of under reporting of fat intake in obese men. Also there was no measured serving sizes only estimated serving portions were used for analysis. It is very difficult to assess dietary intake in a free living population since it is hard to measure portion sizes consumed and the validity of the self reporting. Such results were also obtained by Atkins and Davis (2000) on children aged 1.5- 4.5 years. In their study the children were divided into tertiles based on the percentage fat consumed to determine if there were any mean differences between the tertiles and the differences were not significant.

In studies where controlled experiments have been done on fat consumption, the results have indicated that fat intake is correlated to adiposity. Such a study was done by Klegles et al (1995), in which it was concluded that fat intake, not total energy intake was a significant predictor of obesity in preschool children. Blundell et al, (1997) also carried out a controlled study on fat and carbohydrate intake and their effect on satiety and concluded that fat is inferior to carbohydrate in suppressing hunger and appetite and thus may lead to overeating resulting to 
weight gain. Similar results were obtained by Ledikwe at al, (2006) where it was concluded that fat may increase obesity prevalence due to its high density. 


\section{CHAPTER 6}

\section{CONCLUSION}

The aim of the study was to determine which of the measured variables were the best predictors of obesity in rural West Virginia, among preschool children enrolled in Head Start program. Of the variables measured, the manner in which parents perceive the weight of their children was the strongest and the only significant predictor. However father's education and sugar content in food were also relatively strong. Fat content in the food was the lowest variable in terms of obesity prediction. Although sugar level was a relatively strong predictor, it had a negative correlation to the BMI z-score which means rejection of the null hypothesis. This could be as a result of the way in which the data was collected since data collection was by self reporting of the food consumed and serving sizes were not measured. Conclusive results may be obtained if done under controlled conditions and fat and sugar content measured to reduce bias due to underreporting.

Long term goal of the study is to establish a feasible, family based intervention that would include nutrition education for the parents. Based on this study, parents have a substantial influence on the diet and the lifestyle of their children. These habits form early and tend to persist in adulthood. By focusing on the parents, there can be change in habits and dietary patterns that promote obesity and so the children will grow up adopting healthy nutrition patterns that may reduce risk of obesity related chronic diseases. 


\section{LITERATURE CITED}

1. Albu Jenine and Allison David. Obesity solutions: Report of a meeting. Nutritional Reviews. 1997; 55(5): 150-157.

2. Atkin L, Davies P. Diet composition and body composition in preschool children. Am J Clin Nutr. 2000; 72: 15- 21.

3. Baughcum A E, Chamberlin L A, Deeks C M, Powers S W, Whittaker R C. Maternal perceptions of overweight preschool children. Pediatrics. 2000; 106(6):1380- 1386.

4. Birch L L. Dimensions of preschool children's food preferences, J Nutr Educ.1979; 11: 7780.

5. Birch L.L, Davidson K.K. Family environmental factors influencing the developing behavioral controls of food intake and childhood overweight. Pediatrics Clinics of North America 2004; 48:894- 907.

6. Birch L L and Deysher M. Caloric compensation and sensory satiety: evidence for self regulation of food intake by young children. Appetite. 1986; 7: 323- 331.

7. Birch L, Marlin D, Rotter J. Eating as the "means" activity in a contingency: effects on young children's food preference. Child Development. 1984; 55:431- 439.

8. Bittman M. 1998. The changing boundary between home and market, Australian trends in outsourcing domestic labor. Report no. 86, Sydney: Social policy research center, University of New South Wales.

9. Blundell J E, MaCDiamid J. Fat as a risk factor for over consumption; satiation, satiety and patterns of eating. J. Am. Diet. Assoc. July 1997; 97(7): S63- S69.

10. Bowman SA, Linn M, Gerrior SA, Basiotis P P. The Health Eating Index 19941998. Washington DC: US Department of Agriculture 1998 (CNPP- 5). 
11. Brener D N, Eaton D K, Lowry R, MacManus T. The association between weight perception and BMI among high school students. Obesity Research. 2004; 12(11): 1866 - 1874.

12. Cataldo C, Debruyne L, Whitney E. Nutrition and Diet Therapy, $6^{\text {th }}$ ed., 2003.

13. Constanzo P R, Woody E.Z. Domain specific parenting styles and their impact on the child's development of particular deviance: the example of obesity proneness. Journal of Social and Clinical Psychology .1985; 4: 425- 445.

14. Crooks, Debora. Child growth and nutritional status in a high poverty community in eastern Kentucky. American Journal of Physical Anthropology. 1999; 109:129- 142.

15. Cook J. T., Frank D.A., Levenson S. M., Neault N. B., Heeren T. C., Black M.M., Berkowitz C., Casey P.H., Meyers D.B., Cutts D.B., Chilton M. Child food insecurity increases risks posed by household food insecurity to young children's health. Journal of Nutrition.2006; 136: $1073-1076$.

16. Demerath E., Muratova V., Spangler E., Li J., Minor V. E., Neal W. A. School- based obesity screening in rural Appalachia. Preventive Medicine, 2003; 37:553- 560.

17. Etelson D., Brand D A., Patrick P A., Shirali A. Childhood obesity: Do parents recognize this health risk? Obesity Research. 2003; 11(11): 1362- 1368.

18. Fisher J. and Birch L. Fat preferences and fat consumption of 3-to 5-year old children are related to parental adiposity. Journal of American Dietetic Association, July 1995;95 (7): 759- 764

19. Freedman DS, Dietz WH, Tang R, Mensah GA, Bond MG, Urbina EM, Srinivasan S, Berenson GS. The relation of obesity throughout life to carotid intima- media thickness in adulthood: the Bogalusa Heart Study. Int J Obes Relat Metab Disord. 2004; 28 (1): 159- 66. 
20. Gazzaniga J M and Burns T L. Relationship between diet composition and body fatness with adjustment for resting energy expenditure and physical activity in pre adolescent children. American Journal of Clinical Nutrition. 1993:58:21-28

21. Giammattes J, Blix G, Marshak H H, Wollitzer A O, Pettitt D J. Television watching and soft drink consumption. Associations with obesity in $11-13$ year old schoolchildren. Arch Pediatr Adolesc Med. 2003; 157:882-886.

22. Gibson EL, Wardle J, Watts C.J. Fruit and vegetable consumption, nutritional knowledge and beliefs in mothers and children. Appetite. 1998;31 :205- 8

23. Gordana M, Levitsky D A. Children eat what they are served: the imprecise regulation of energy intake. Appetite. 2005; 44(3): 273- 282.

24. Goris A, Plantenga M, Westerterp K. Undereating and underrecording of habitual food intake in obese men: selective underreporting of fat intake. Am J Clin Nutr. 2007; 71:130- 4.

25. Hill J O and Prentice A M. Sugars and body weight regulation. Amer. J of Clin. Nutr. 1995; 62(suppl): 264S- 74S.

26. Jago R, Baranowski T, Baranowski J C, Thompson D, Greaves KA. BMI from 3- 6y of age is predicted by TV viewing and physical activity, not diet. International Journal of Obesity. 2005; 29: 557- 564.

27. Johnson S and Birch L. Parent's and children's adiposity and eating style. Pediatrics. 1994; 94: $653-661$.

28. Klesges R, Klesges L, Eck L, Shelton M. Longitudinal analysis of accelerated weight gain in preschool children. Pediatrics. 1995; 95: 126-130.

29. Krause's Food, Nutrition and Diet Therapy11th ed. Mahan K., Escott-stump S. 2004. 
30. Klohe-Lehman DM, Freeland-Graves J, Anderson ER, McDowell T, Clarke KK, Hanss-Nuss H, Cai G, Puri D, Milani T.J. Nutritional knowledge is associated with greater weight loss in obese and overweight low income mothers. J Am Diet Assoc. 2006; 106(1): 65- 75.

31. Kvaavik E, Andersen L, Klepp K. The stability of soft drinks intake from adolescence to adult age and the association between long-term consumption of soft drinks and lifestyle factors and body weight. Public Health Nutrition. 2004; 8(2): 149- 157.

32. Lafay L, Mennen L, Basdevant A, Charles M, Borys J, Eschwege E. Does energy intake underreporting involve all kinds of food or only specific food items? Results from the Fleurbaix Laventie Ville Sante' (FLVS) study. International Journal of Obesity. 2000; 24: 1500- 1506.

33. Ledikwe J H, Blanck H M, Khan K L, Serdula M K, Seymour J D, Tohill B C, Rolls B J. Dietary energy density is associated with energy intake and weight status in US adults. Am J Clin Nutr. 2006; 83:1362-8

34. Lino M, Basistis P, Gerror S, Carlson A. The quality of young children's diet. Family Economics and Nutritional Review.2002; 14(1):52-60.

35. Lissner L, Levitsky A D, Strupp J B, Kalkwarf H J, Roe A D. Dietary fat and the regulation of energy intake in human subjects. American Journal of Clinical Nutrition .1987:46: 889-92.

36. Lowenberg ME. Development of food patterns in young children. In Trahms CM, Pipes P: Nutrition in Infancy and Childhood, $6^{\text {th }}$ ed., St Louis, 1997, WCB/McGraw-Hill.

37. Martin K.S., Ferris A. M. 2007. Food insecurity and gender are risk factors for obesity. Journal of Nutrition Educational Behavior.2007; 39:31- 36.

38. Maynard M L, Galuska D A, Blanck H M, Serdula M K. Maternal perceptions of weight status of children. Pediatrics. 2003; 111(5):1226- 1231. 
39. Must A, Jacques P, Dallal G, Bajema C, Dietz W. Long-term morbidity and mortality of overweight adolescents. A follow up of Harvard Growth Study of 1922 to 1935. N Engl. J Med. 1992; 327: 1350- 1355.

40. Myers, Sue, Vargas, Zulma. Parental perceptions of the preschool obese child. Pediatric Nursing. Jan 2000; 26(1):23-31.

41. Overby N C, Lillegaard I T, Johansson L, Andersen L. High intake of added sugar among Norwegian children and adolescents. Public Health Nutrition. 2003; 7(2):285- 293.

42. Perruse L and Bouchard C., 1999. Genotype- environment interaction in human obesity, Nutrition Review 57:S31- S38.

43. Poppitt S D, Prentice A M. Energy density and its role in the control of food intake: Evidence from metabolic and community studies. Appetite, 1996; 26:153- 174.

44. Ravussin T, and Tataranni A. Dietary fat and human obesity. J of Amer. Diet. Assoc. July 1997; 97:\#7 suppl. S42- S46.

45. Ravussin E, Valencia M, Esparza J, Bennett P, Schulz L. Effects of a traditional lifestyle on obesity in Pima Indians. Diabetes care. 1994; 17:1067- 1074.

46. Srinivasan S, Myers L, Berenson G. Predictability of childhood adiposity and insulin for developing insulin resistance syndrome (syndrome $\mathrm{X}$ ) in young adulthood. The Bogalusa Heart Study. Diabetes. 2002; 51: 204-209.

47. Stunkard A, Sorensen T, Hanis C, Teasdale T, Chakraborty R, Schull W, Schulsinger F. An adoption study of human obesity. N Engl J Med. 1986; 314:193- 198.

48. Sullivan S, Birch LL. Pass the sugar, pass the salt :experience dictates preference. Dev Psychol.1990;26:546- 551. 
49. Thakur N, D'Amico F. Relationship of nutrition knowledge and obesity in adolescence. Family Medicine 1999; 31(2):122-7.

50. Utter J, Scragg R, Schaaf D. Associations between television viewing and consumption of commonly advertised foods among New Zealand children and young adolescents. Public Health Nutrition. 2005; 9(5): 606- 612.

51. Vereecken C A, Todd J, Roberts C, Mulvihill C, Maes L. Television viewing behavior and associations with food habits in different countries. Public Health Nutrition. 2005; 9(2):244250.

52. West Virginia Department of Health and Human Resources Bureau for Public Health, Office of Epidemiology and Health promotion. Obesity, Facts Figures and Guidelines. Dec. 2002.

53. West Virginia Department of Health and Human Resources, Bureau for Public Health, Office of Epidemiology and Health Promotion. Health Statistics Center, 1988- 1993.

54. Whitaker R C, Wright J A, Pepe M S, Seidel K D, Dietz W H. Predicting obesity in young adulthood from childhood and parental obesity. The New England Journal of Medicine. 1997; 337(13): 869- 73. 


\begin{abstract}
Appendix A
Parental or Guardian Consent and Information Form

Factors Affecting Intake, Growth, and Body Mass Index of Preschool Children
\end{abstract}

\title{
Introduction
}

I, , have been asked to allow my child to participate in a research study that examines the factors that affect intake and growth among children aged three to five years. Cindy Fitch, Ph.D., RD who is conducting this research at West Virginia University has explained the study to me. I understand that the money to pay for this study is being provided by the United States Department of Agriculture.

\section{Purposes of the Study}

I understand that the purpose of this study is to learn more about factors that influence intake, growth, and weight gain of children aged three to five years.

\section{Description of Procedures}

This study will be performed at a church, day care, or Head Start center that my child attends or at the county WVU Extension office. My child will be weighed and measured and I will be asked to report everything he/she eats or drinks for two 24-hour periods. I will also be asked to fill out a series of questionnaires. I understand that it will take about 1 hour of my time for the diet history and questionnaires. I have been given an opportunity to examine the questionnaires. Approximately 300 children will be enrolled in this study.

\section{Benefits}

I understand that this study is not expected to be of direct benefit to my child but the knowledge gained may be of benefit to others.

\section{Risks and Discomforts}

There are no known or expected risks from participating in this study.

\section{Financial Considerations}

I understand that there is no cost to me for participation in this study and I will receive a grocery store gift certificate for $\$ 20.00$ as a token of appreciation for my time.

Initials Date 
Appendix B

ID Number

Date

Information Form

Child's Date of Birth

Age (months)

Growth Parameters

Child's Weight

WAP

HAP

Child's Height

WHP

WHZ
WAZ

HAZ

BMI percentile 


\section{Appendix C}

\section{Parent Information Form}

ID Number

Mother's Age

Less than 20 years

20 to 29 years

30 to 39 years

40 to 49 years

50 years or greater

Mother's height

Mother's weight

Number of adults in home

Who is primarily responsible for food purchases?

Food preparation?

Mother's education level

Less than 12 years

High school diploma or equivalent

Some college courses

College degree

Graduate degree

\section{Mother's Occupation}

Number of hours worked per week
Father's Age

Less than 20 years

20 to 29 years

30 to 39 years

40 to 49 years

50 years or greater

Father's height

Father's weight

\author{
Father's education level \\ Less than 12 years \\ High school diploma or equivalent \\ Some college courses \\ College degree \\ Graduate degree
}

\section{Father's Occupation}

Hours worked per week

How many hours per day does your child spend watching television or videos? Playing video or computer games?

Does he/she have a television in his/her room? 


\section{Appendix D}

Mother's Nutrition Knowledge and Health Awareness

Which has more fiber? (Circle the best answer.)

Fruit or meat

Cornflakes or oatmeal

Whole-wheat bread or white bread

Orange juice or an apple

Kidney beans or lettuce

Popcorn or pretzels

Which has more cholesterol?

Liver or T-bone steak

Butter or margarine

Egg whites or yolks

Skim milk or whole milk

Which has more fat?

Regular hamburger or ground round

Loin pork chops or pork spare ribs

Hot dogs or ham

Peanuts or popcorn

Yogurt or sour cream

Porterhouse steak or round steak

Ice cream or sherbet

Roast chicken leg or fried chicken leg

Which kind of fat (saturated or polyunsaturated) is more likely to be a liquid than a solid? Or are they equally likely to be liquid?

Is cholesterol found in vegetables and vegetable oils, animal products, or all foods containing fat and oil?

If a food is labeled cholesterol-free, is it also low in saturated fat, high in saturate fat, or either?

Have you hear about any health problems that might be related to how much:

$\begin{array}{lcc}\text { Fat a person eats? } & \text { Y } & \text { N } \\ \text { Saturate fat a person eats? } & \text { Y } & \text { N } \\ \text { Fiber a person eats? } & \text { Y } & \text { N } \\ \text { Salt a person eats? } & \text { Y } & \text { N } \\ \text { Calcium a person eats? } & \text { Y } & \text { N } \\ \text { Cholesterol a person eats? } & \text { Y } & \text { N } \\ \text { Sugar a person eats? } & \text { Y } & \text { N } \\ \text { Iron a person eats? } & \text { Y } & \text { N } \\ \text { A person is overweight? } & \text { Y } & \text { N }\end{array}$




\section{Appendix E}

\section{Child Feeding Questionnaire}

Please circle the best answer for each question.

1. When your child is at home, how often are you responsible for feeding him or her?

1. never

2. seldom

3. half of the time

4. most of the time

5. always

2. How often are you responsible for deciding what your child's portion sizes are?
1. never
2. seldom
3. half of the time
4. most of the time
5. always

3. How often are you responsible for deciding if your child has eaten the right kind of food?
1. never
2. seldom
3. half of the time
4. most of the time
5. always

4. Which of the following best describes your childhood (5 to 10 years old)?
1. markedly underweight
2. underweight
3. normal
4. overweight
5. markedly overweight

5. Which of the following best describes your adolescence?
1. markedly underweight
2. underweight
3. normal
4. overweight
5. markedly overweight

6. Which of the following best describes your $20 \mathrm{~s}$
1. markedly underweight
2. underweight
3. normal
4. overweight 
5. markedly overweight

7. Which of the following best describes you at present?

1. markedly underweight

2. underweight

3. normal

4. overweight

5. markedly overweight

8. Which of the following best describes your child during the first year of life?

1. markedly underweight

2. underweight

3. normal

4. overweight

5. markedly overweight

9. Which of the following best describes your child as a toddler?

1. markedly underweight

2. underweight

3. normal

4. overweight

5. markedly overweight

10. Which of the following best describes your child as a preschooler?

1. markedly underweight

2. underweight

3. normal

4. overweight

5. markedly overweight

11. How concerned are you about your child eating too much when you are not around?

1. unconcerned

2. a little concerned

3. concerned

4. fairly concerned

5. very concerned

12. How concerned are you about your child having to diet to maintain a desirable weight?

1. unconcerned

2. a little concerned

3. concerned

4. fairly concerned

5. very concerned 
13. How concerned are you about your child becoming overweight?
1. unconcerned
2. a little concerned
3. concerned
4. fairly concerned
5. very concerned

14. I have to be sure that my child does not eat too many sweets (candy, ice cream, or cake).

1. disagree

2. slightly disagree

3. neutral

4. slightly agree

5. agree

15. I have to be sure that my child does not eat too many high-fat foods.
1. disagree
2. slightly disagree
3. neutral
4. slightly agree
5. agree

16. I have to be sure that my child does not eat too much of his/her favorite food.
1. disagree
2. slightly disagree
3. neutral
4. slightly agree
5. agree

17. I intentionally keep some foods out of my child's reach.
1. disagree
2. slightly disagree
3. neutral
4. slightly agree
5. agree

18. I offer sweets (candy, ice cream, and cake) to my child as a reward for good behavior.

1. disagree

2. slightly disagree

3. neutral

4. slightly agree

5. agree 
19. I offer my child his/her favorite foods in exchange for good behavior.

1. disagree

2. slightly disagree

3. neutral

4. slightly agree

5. agree

20. If I did not guide or regulate my child's eating, he/she would eat too many junk foods.

1. disagree

2. slightly disagree

3. neutral

4. slightly agree

5. agree

21. If I did not guide or regulate my child's eating, he/she would eat too much of his/her favorite foods.
1. disagree
2. slightly disagree
3. neutral
4. slightly agree
5. agree

22. My child should always eat all of the food on his/her plate.
1. disagree
2. slightly disagree
3. neutral
4. slightly agree
5. agree

23. I have to be especially careful to make sure my child eats enough.
1. disagree
2. slightly disagree
3. neutral
4. slightly agree
5. agree

24. If my child says "I'm not hungry", I try to get him/her to eat anyway.
1. disagree
2. slightly disagree
3. neutral
4. slightly agree
5. agree 
25. If I did not guide or regulate my child's eating, he/she would eat much less than he/she should.
1. disagree
2. slightly disagree
3. neutral
4. slightly agree
5. agree

26. How much do you keep track of the sweets (candy, ice cream, cake pies, pastries) that your child eats?
1. never
2. rarely
3. sometimes
4. mostly
5. always

27. How much do you keep track of the snack food (potato chips, Doritos, cheese puffs) that your child eats?
1. never
2. rarely
3. sometimes
4. mostly
5. always

28. How much do you keep track of the high fat foods that your child eats?
1. never
2. rarely
3. sometimes
4. mostly
5. always 


\section{ACKNOWLEDGEMENTS}

I would like to thank my committee members, Dr Fitch, Mrs. Forbes and Dr. Matak, for their guidance and support throughout this study.

Special thanks also go to the late Dr Seidel for his valuable input in the analysis of the data. I would also like to thank West Virginia extensions officers for their great help in the collection of the data and all the individuals from Mercer and MacDowell counties that participated in the study.

Lastly, special thanks go to my family, Samuel and Chelsea Gecheo for their support and patience during the entire study. 